\title{
The pedagogical effect of a health education application for deaf and hard of hearing students in elementary schools
}

\author{
Masoumeh Abbasi ${ }^{1}$, Saeid Eslami ${ }^{2,3}$, Mahdi Mohammadi ${ }^{1}$, Reza khajouei ${ }^{4,5}$
}

${ }^{1}$ Student Research Committee, Department of Medical Informatics, Faculty of Medicine, Mashhad University of Medical Science, Mashhad, Iran

${ }^{2}$ Ph.D., Associate Professor, Pharmaceutical Research Center, School of Pharmacy, Mashhad University of Medical Sciences, Mashhad, Iran

${ }^{3}$ Ph.D., Associate Professor, Department of Medical Informatics, Faculty of Medicine, Mashhad University of Medical Sciences, Mashhad, Iran

${ }^{4} \mathrm{Ph} . D$., Associate Professor, Medical Informatics Research Center, Institute for Futures Studies in Health, Kerman University of Medical Sciences, Kerman, Iran

${ }^{5}$ Ph.D., Associate Professor, Department of Health Information Management and Technology, Faculty of Management and Medical Information Sciences, Kerman University of Medical Sciences, Kerman, Iran

\section{Type of article: Original}

\begin{abstract}
Background: Deaf or hard-of-hearing children experience difficulties in learning health principles. But technology has significantly improved their ability to learn. The challenge in e-learning is to design attractive applications while having an educational aspect.

Objective: The aims of this study were to determine the pedagogical effectiveness of a health education application for deaf and hard of hearing students in elementary schools, and to investigate the student's perceptions in different educational grades about the educational effectiveness of the text, graphics, video clips, and animation in the application.

Methods: The study design was quasi experimental and was conducted in Mashhad in 2016. Study population were deaf or hard-of-hearing students in elementary schools. The intervention included health application training to deaf and hard-of-hearing students in Mashhad. A questionnaire was used for data gathering. The pedagogical effectiveness was determined by measuring the modified Adapted Pedagogical Index. This index was created based on the characteristics of the application and study population. Statistical analysis was performed using the Kruskal-Wallis and Mann-Whitney tests with Bonferroni adjustment by SPSS 22.

Results: Eighty-two students participated in the intervention. The value of modified Adapted Pedagogical Index was 0.669 , indicating that the application was effective. The results of Kruskal-Wallis H and Mann-Whitney U test showed significant differences in different educational grades. $(\mathrm{p}<0.008)$

Conclusion: Using information technology can improve the education of deaf and hard-of-hearing students. Modified Adapted Pedagogical Index can be used for evaluation of non-interactive applications for elementary school children who are deaf or hard of hearing.

Keywords: Deafness; Health Education; Evaluation Studies; Hearing Disabled; Student
\end{abstract}

\section{Introduction}

Deafness means profound hearing loss; the related term hard of hearing refers to people with hearing loss that is of a slightly lower degree than deafness. Over $5 \%$ of the world's population - 360 million people - have a hearing lossrelated disability (1). In Iran, one thousand infants are born with hearing loss every year (2). Children who are deaf

\section{Corresponding author:}

Associate Professor Dr. Reza Khajouei, Kerman University of Medical Sciences, Kerman, Iran.

Tel: +98.9132969727, Email: R.khajouei@yahoo.com

Received: January 04, 2017, Accepted: March 15, 2017, Published: September 2017

iThenticate screening: February 13, 2017, English editing: June 16, 2017, Quality control: July 06, 2017

This article has been reviewed / commented by three experts

(C) 2017 The Authors. This is an open access article under the terms of the Creative Commons Attribution-NonCommercialNoDerivs License, which permits use and distribution in any medium, provided the original work is properly cited, the use is non-commercial and no modifications or adaptations are made. 
or hard-of-hearing experience more problems in language comprehension than their hearing peers. They have limitations during social interaction (3), and their vocabulary and grammatical knowledge are generally less developed than in those without hearing loss (4). Reflecting these circumstances, children who are deaf or hard-ofhearing struggle to learn health principles (5) and have lower access to health care than the general population (6). Depression and stress (among other mental disorders) are more prevalent in this group $(6,7)$. Providing educational programs based on the needs of those who are deaf - that is, in an appropriate form and language - is recommended to solve these problems (8). Over the years, technology has significantly improved the ability to learn for people who are deaf or hard-of-hearing (3). Various technologies have been created for deaf education; for example, X University's Signing Avatar (XUSA) to teach computer science concepts to deaf and hearing-impaired students and sign language interpreters (9), multimedia educational software (4), and e-learning courses (ECDL) (10). My Body, My Responsibility is a health education project for deaf and hard-of-hearing women of different ages (11). Although the use of Information and Communication Technology has benefits for people with disabilities, problems exist in access to this technology, usability, and compliance with different needs and learning styles (12). The challenge in e-learning is designing applications that remain attractive for learners while having an educational aspect (13). According to Stockwell (14), the relationship between technology and pedagogy is symbiotic, with interdependent benefits and disadvantages. In Iran, deaf students suffer from many specific health problems more frequently than do other students, including underdeveloped social skills, low levels of life satisfaction (15), and oral diseases (5), while they work from the same textbooks as all other students. The Health Education Application (16) reviewed herein is designed for the provision of health education to deaf and hard-of-hearing students in elementary schools in Iran. The application includes age-appropriate video clips and animation. We conducted this study with two aims. First, to determine the pedagogical effectiveness of a health-education application for deaf and hard-of-hearing students in elementary schools; Second, to investigate the perceptions of students in different educational grades about the educational effectiveness of the text, graphics, video clips, and animation.

\section{Material and Methods}

\subsection{Study design}

The evaluation was designed as a quasi-experimental study with only post-test that included intervention and then measurement of the outcome without a control group. The study was conducted in Mashhad in 2015.

\subsection{Participants}

At the time of the study, a total of 116 students were in schools for the deaf in Mashhad. Inclusion criteria were all the deaf or hard-of-hearing students from third to sixth grade. Students in the first and second grade were not included in the study because of their inability to read subtitles or comprehend the questions of the questionnaire. Exclusion criteria included students who had any other disabilities.

\subsection{Setting}

This study examined the pedagogical effectiveness of a health-education application in elementary school students who were deaf or hard-of-hearing. To this end, an evaluation was performed in elementary schools in Mashhad, Iran. In Iran, elementary schools have six grades. There are two elementary schools for children who are deaf or hard-of-hearing in Mashhad; one is specifically for boys, the other for girls.

\subsection{Health-education Application}

The health-education application used in this study, developed by Ahmadi (16), is the application for health education orientated to the needs of children who are deaf or hard-of-hearing. Briefly, the application includes ten educational video clips and two animations in five main categories: body health ( 2 video clips), ear health ( 3 video clips), oral health (3 video clips, 2 animations), mental health (1 video clip), and personal health items (1 video clip). Each video clip has subtitles, pictures about content in the top right corner of the video clip, Persian Sign Language (PSL), and sound. Animations depict the proper use of dental floss and toothbrush. The Application is offline and in the form of a compact disc (CD/DVD). A snapshot of the application is shown in Figure 1.

\subsection{Adapted Pedagogical Index (AdaPI)}

The Adapted Pedagogical Index (AdaPI) (10) is based on the Pedagogical Effectiveness Index (PEI) proposed by Snowalkar (2002) (17) and was adapted for use in those who are deaf or hard-of-hearing. Both the PEI (Table 1) and the AdaPI (Table 2) have three dimensions: learning styles, media, and interaction. Each dimension covers different components, and these components differ in AdaPI compared to PEI to incorporate features specific to those who are deaf or hard-of-hearing. 


\subsection{Modified Adapted Pedagogical Index}

In this study, we changed the AdaPI to make it suitable for use with the non-interactive health application and the specific characteristics of (and challenges facing) students who are deaf or hard-of-hearing in elementary schools. The interactive dimension and material arrangement component were removed as they were not applicable; the video clip component was added to the media dimension. The dimensions and components of the modified AdaPI are shown in Table 3. After incorporation of the aforementioned changes, the questionnaire was modified by excluding questions related to the removed dimensions and components. The validity of the new questionnaire was confirmed by three medical informatics experts. The validated questionnaire contained 16 closed questions; 5 questions were general, while the other 11 questions were used to measure the two dimensions. Responses are based on a 5-point Likert scale that ranged from strongly disagree to strongly agree.

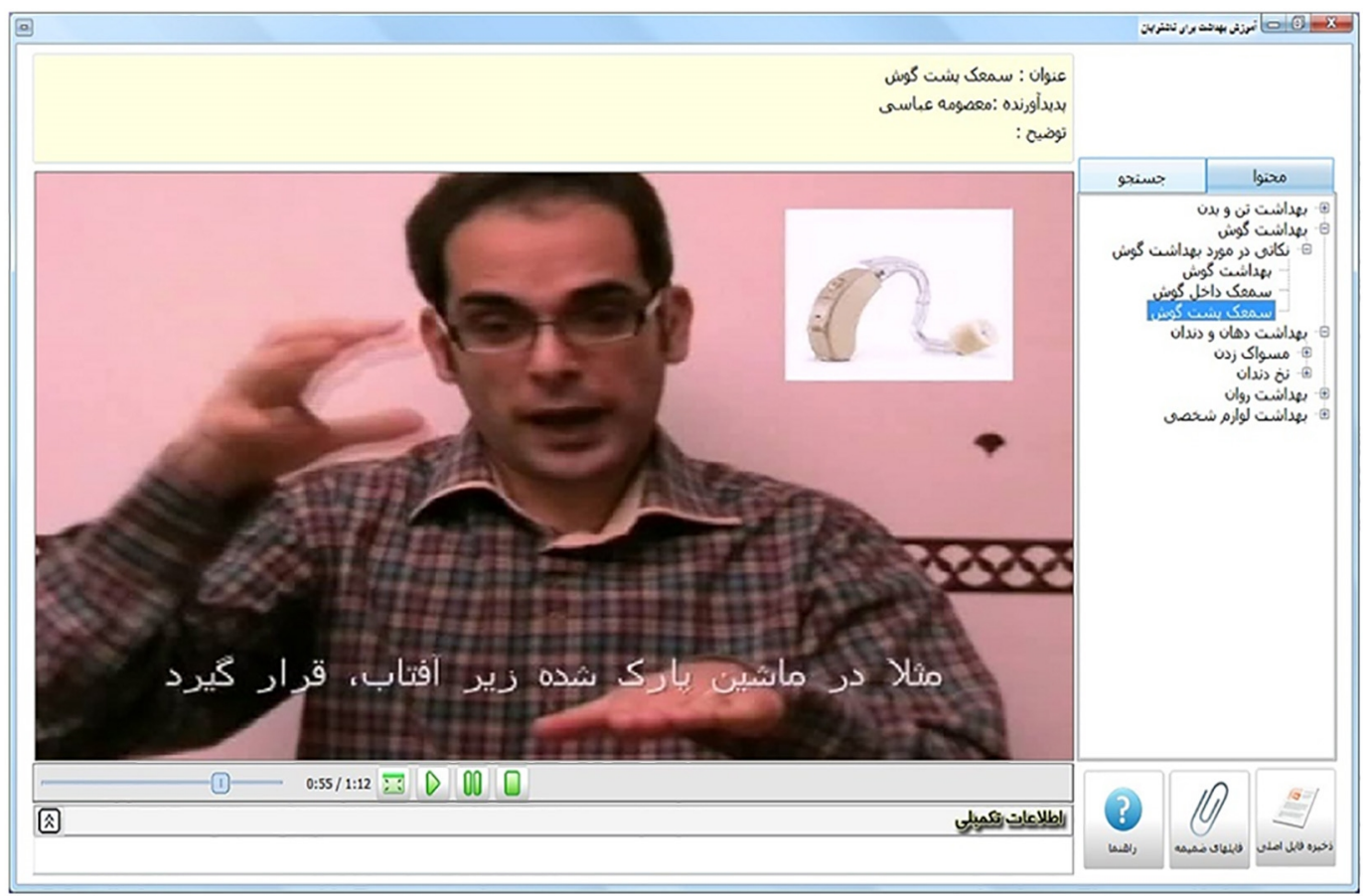

Figure 1. A snapshot of Health Education Application

Table 1. Dimensions and components of PEI (10)

\begin{tabular}{|l|l|}
\hline Dimensions & Components \\
\hline Interaction & Feedback \\
\cline { 2 - 2 } & Revision \\
\cline { 2 - 2 } & Discussion \\
\cline { 2 - 2 } & Email \\
\cline { 2 - 2 } & Bulletin \\
\hline Media & Text \\
\cline { 2 - 2 } & Graphic \\
\cline { 2 - 2 } & Audio \\
\cline { 2 - 2 } & Animation \\
\cline { 2 - 2 } & Simulation \\
\hline Learning Styles & Apprenticeship \\
\cline { 2 - 2 } & Incidental Learning \\
\cline { 2 - 2 } & Inductive \\
\cline { 2 - 2 } & Deductive \\
\cline { 2 - 2 } & Discovery \\
\hline
\end{tabular}


Table 2. Dimensions and components of AdaPI (10)

\begin{tabular}{|l|l|}
\hline Dimensions & Components \\
\hline Interaction & Feedback \\
\cline { 2 - 2 } & Revision \\
\cline { 2 - 2 } & Discussion \\
\cline { 2 - 2 } & Email \\
\cline { 2 - 2 } & Tutor's Role \\
\hline \multirow{5}{*}{ Media } & Text \\
\cline { 2 - 2 } & Graphic \\
\cline { 2 - 2 } & Audio \\
\cline { 2 - 2 } & Animation \\
\cline { 2 - 2 } & Material Arrangement \\
\hline Learning Style & Apprenticeship \\
\cline { 2 - 2 } & Incidental Learning \\
\cline { 2 - 2 } & Discovery \\
\cline { 2 - 2 } & VAK Styles (Visual, Auditory, Kinesthetic) \\
\hline
\end{tabular}

Table 3. Dimensions and components of Modified AdaPI

\begin{tabular}{|l|l|}
\hline Dimensions & Components \\
\hline Media & Text \\
\cline { 2 - 2 } & Graphic \\
\cline { 2 - 2 } & Audio \\
\cline { 2 - 2 } & Animation \\
\cline { 2 - 2 } & Video Clips \\
\hline Learning Styles & Apprenticeship \\
\cline { 2 - 2 } & Incidental Learning \\
\cline { 2 - 2 } & Discovery \\
\cline { 2 - 2 } & VAK Styles (Visual, Auditory, Kinesthetic) \\
\hline
\end{tabular}

\subsection{Intervention}

Intervention was done by presenting the health education application to the students in elementary schools. Students in each educational grade watched the video clips and animations of the application. Each session took about half an hour. The intervention was conducted in May 2015 and lasted one month. The presentation to students was given in a room where a computer was available for the students. Other elementary-school classrooms do not have computers. After the health teachers confirmed the completion of training, the questionnaire was distributed to students for measurement of the educational effectiveness. Teachers had a study assistant role in this study.

\subsection{Research Ethics}

Students and teachers who participated in evaluating were completely voluntary. Student's names and the student's identifiable profile information, was not recorded. Students were not informed of each other's answers. Permission for research in deaf schools was granted by the Special Education Organization in Mashhad.

\subsection{Analysis}

A value of 0 to 4 was assigned to the responses of each question, with 0 indicating "strongly disagree" and 4 indicating "strongly agree". After the average value of each component was calculated $\left(v_{j}\right)$, the weight of each dimension $v_{i}$ was computed (10). The final result, Modified AdaPI, is computed by the sum of the $v_{i} \mathrm{~s}$, with its value being zero to one. The value of modified AdaPI is in the range of 0 to 1 . The result of Modified AdaPI is compared with constant value of 0.5 that indicates the mean value of modified AdaPI. For this equation, values above 0.5 indicated the pedagogical effect of the health application. We investigated the hypothesis that a difference exists between the perceptions of students in different educational grades about the educational effectiveness of media components (text, graphics, video clips, and animations). According to the data, distribution was not normal so Kruskal-Wallis and Mann-Whitney nonparametric tests were used. The Kruskal-Wallis test shows the difference in the groups. To assess the difference between the two education grades, the Mann-Whitney U test was used. Bonferroni correction is used as an adjustment method for multiple comparisons by dividing the critical $p$ value $(\alpha)$ 
on the number of comparisons. The Audio component was removed from analysis. Data for statistical analysis was based on a 5-point Likert scale (1-5); analyses were performed using SPSS 22 (SPSS; Chicago, Illinois, USA).

\section{Results}

Eighty-two deaf or hard-of-hearing students (46 boys, 36 girls) were the intervention group. Of these students, 26 were from sixth educational grade and the number of students in third, fourth and fifth educational grades respectively was 18,19 and 19 students. After one month of using the health education application, evaluation was done. The highest and lowest means belong to the learning style dimension. The VAK component has the highest mean (4), and Incidental Learning has the lowest mean (0.62). Except for the Audio component (0.62), the mean values of all components of the media dimension are higher than the median of the points (3). The calculated weight of the learning styles was 1.95 and media dimensions was 3.44. The total value of the AdaPI was 0.669 . The results of the Kruskal-Wallis $\mathrm{H}$ test confirmed the hypothesis that difference exists between the perceptions of students in different educational grades about the educational effectiveness of media components (Table 4). The results of the Mann-Whitney U test for comparing the two different educational grades together is shown in Table 5.

Table 4. Results of Kruskal-Wallis test for media components among different educational grades

\begin{tabular}{|l|l|l|l|l|l|}
\hline \multirow{2}{*}{ Media Components } & \multicolumn{3}{|l|}{ Mean of scores for educational grades } & p-value $(\alpha=0.05)$ \\
\cline { 2 - 5 } & Third & Fourth & Fifth & Sixth & \\
\hline Text & 3.55 & 3.92 & 4.52 & 4.57 & 0.001 \\
\hline Graphics & 4.22 & 4.58 & 5 & 4.69 & $<0.001$ \\
\hline Animation & 4.33 & 4.68 & 5 & 5 & $<0.001$ \\
\hline Video clips & 4.33 & 4.50 & 4.50 & 4.50 & $<0.001$ \\
\hline
\end{tabular}

Table 5. Results of Mann-Whitney U Test

\begin{tabular}{|l|l|l|l|l|}
\hline Grades & Text & Graphics & Animation & Video \\
\hline Third \& Fourth & $<0.001^{*}$ & 0.050 & 0.035 & $0.007^{*}$ \\
\hline Third \& Fifth & 0.116 & $<0.001^{*}$ & $<0.001^{*}$ & $0.007^{*}$ \\
\hline Third \& Sixth & $<0.001^{*}$ & 0.016 & $<0.001^{*}$ & $0.002^{*}$ \\
\hline Fourth \& Fifth & 0.172 & 0.009 & 0.008 & 1 \\
\hline Fourth \& Sixth & 0.986 & 0.864 & $0.002^{*}$ & 1 \\
\hline Fifth \& Sixth & 0.185 & 0.008 & 1 & 1 \\
\hline
\end{tabular}

${ }^{*}$ The significant level is 0.008 using a Bonferroni correction.

\section{Discussion}

This study was conducted to determine the effect of a health-education application for elementary school students who are deaf or hard-of-hearing. To the best of our knowledge, this application is the first and only health-education application for deaf and hard-of-hearing students in Iran, to date. The calculated value of the Modified Adapted Pedagogical Index was 0.669 , indicating that the students believed in the pedagogical effect of the application. This study was carried out to determine the interest that deaf and hard-of-hearing students have in learning, using information technology in their classrooms. The highest mean value belongs to the VAK component from the learning style dimension. Teachers, students, and others conceive of those who are deaf as having a predominantly visual learning style (18). Thus, all of the students gave the highest rating to questions related to a visual learning style. Results of studies $(19,20)$ on the effectiveness of video sources in deaf education have shown the important role of visual communication for deaf children. Incidental Learning or natural learning method (21) happens mostly when computers are used during the completing tasks in the workplace $(22,23)$, or by observation or conversation to coworkers or specialists about tasks (24). The lowest mean is the Incidental Learning or mean from the learning style dimension. Because our application does not practice this, and the intervention lasted one month, there was no ample opportunity for discussion about the video clips. The health education application is not interactive. Our focus in designing the first health application in Iran was on the health-needs assessment of the students and on evaluating the effectiveness of the health application. In this application, there are educational video clips. Thus, a video clip component was added to the media dimension for evaluation. The aim of the statistical test, was to find whether the software is suitable for all educational grades or should it be changed proportional to the students' interests about components of the media dimension. The results showed (Table 5) significant differences among the components of the media dimension in different educational grades based on the students' perceptions. Therefore, the components of the media dimension should separately change for each educational grade level. For example, comparison 
between text component means in educational grades, showed that the mean in the third grade is the lowest and in the sixth grade is the highest. As a result, text should be lower than other grades in the development of software for third grade students. The degree of hearing loss of students in the different educational grades is unknown. Thus, evaluation of the Audio component did not yield accurate information and was deleted from the analysis. In elementary schools in this study, only one classroom in each school has a computer. So, the application was not used sufficiently and students in one of the classes could watch the clips only once. This may have led to underestimation of the result. The results of the study by Agboola and Lee (25) showed that the lack of access to technology for the deaf and hard-of-hearing is a major cause of improper training in (and overall low levels of) digital literacy. The result of the studies of Liu et al. (26), Baker (27) and Hussein and Al-Nisour (28) indicated the positive effect of technology in the education of the deaf and hard-of-hearing. There are limitations in this study. The application was evaluated in a single center. But, this center is in the second most-populated city in Iran and the education system in this country is centralized; the curriculum and teaching materials are similar for all the students. Therefore, this limitation could not significantly diminish the generalizability of the results.

\section{Conclusions}

In summary, the findings showed that using information technology can improve the education of deaf and hard-ofhearing students. The practical importance of these findings is that modified AdaPI can be used for evaluation of non-interactive applications for deaf or hard-of-hearing students in elementary schools. We suggest extending the health application to cover the entire health needs of the students. Complementary research on the effectiveness of health applications to measure the impact of the application on the health behavioral change of deaf and hard-ofhearing students by case-control or before and after methods, could be an appropriate path for future research on this topic.

\section{Acknowledgments:}

We would like to thank all the students and teachers who participated in this study and volunteered their time to complete the tests.

\section{Conflict of Interest:}

There is no conflict of interest to be declared.

\section{Authors' contributions:}

All authors contributed to this project and article equally. All authors read and approved the final manuscript.

\section{References:}

1) WHO Media centre: Deafness and hearing loss: World Health Organization; 2015. Available from: http://www.who.int/mediacentre/factsheets.

2) Noaparast Z. Prediction of deafness prevalence in Iran 2015. Available from: http://www.isna.ir/news/942.

3) Burton M. Evaluation of sign language learning tools: Understanding features for improved collaboration and communication between a parent and a child. Graduate Theses and Dissertations: Iowa State University; 2013.

4) Mazlina AM, Ananthi KM, Herawan T. A Design of Educational Multimedia Software for Disability: A Case Study for Deaf People. The International Conference on Modeling and Simulation. 2012; 2012: 1-8.

5) Shahrabi M, Mohandes F, Seraj B. Assessing DMFT index in 12 years old students attending hearing impaired schools in Tehran. Journal of Dental Medicine. 2006; 19(4): 102-6.

6) Emond A, Ridd M, Sutherland H, Allsop L, Alexander A, Kyle J. The current health of the signing Deaf community in the UK compared with the general population: a cross-sectional study. BMJ Open. 2015; 5(1). doi: 10.1136/bmjopen-2014-006668.

7) Brown PM, Cornes A. Mental Health of Deaf and Hard-of-Hearing Adolescents: What the Students Say. J Deaf Stud Deaf Educ. 2015; 20(1): 75-81. doi: 10.1093/deafed/enu031. PMID: 25237152.

8) Folkins A, Sadler GR, Ko C, Branz P, Marsh S, Bovee M. Improving the Deaf community's access to prostate and testicular cancer information: a survey study. BMC Public Health. 2005; 5: 63. doi: 10.1186/1471-2458-5-63. PMID: 15938751, PMCID: PMC1180455.

9) Andrei S, Osborne L, Smith Z. Designing an American Sign Language Avatar for Learning Computer Science Concepts for Deaf or Hard-of-Hearing Students and Deaf Interpreters. Journal of Educational Multimedia and Hypermedia. 2013; 22(3): 229-42. 
10) Debevc M, Stjepanovic Z, Holzinger A. Development and evaluation of an e-learning course for deaf and hard of hearing based on the advanced Adapted Pedagogical Index method. Interactive Learning Environments. 2012; 22(1): 35-50. doi: 10.1080/10494820.2011.641673.

11) Pollard R. My Body, My Responsibility University of Rochester Medical Center; 2003-2005. Available from: http://www.urmc.rochester.edu.

12) Hersh M. Evaluation framework for ICT-based learning technologies for disabled people. Computers \& Education. 2014; 78: 30-47. doi: 10.1016/j.compedu.2014.05.001

13) Alsumait A, Al-Osaimi A. Usability Heuristics Evaluation for Child E-learning Applications. Journal of Software. 2010; 5(6): 654-61. doi: 10.4304/jsw.5.6.654-661.

14) Wang MJ, Chen HC. Pedagogical Practice and Students' Perceived Effectiveness of Web-based Automated Speech Evaluation. The journal of ASIA TEFL. 2009; 6(4): 217-43.

15) Davoudi I, Kascani RM, Honarmand MM. Social skill, life satisfaction and locus of control in normalhearing and hearing-impaired students. Audiol. 2014; 23(2): 66-73.

16) Ahmadi M, Abbasi M, Bahaadinbeigy K. Design and implementation of a software for teaching health related topics to deaf students: the first experience in iran. Acta Inform Med. 2015; 23(2): 76-80. doi: 10.5455/aim.2015.23.76-80. PMID: 26005271, PMCID: PMC4430007.

17) Sonwalkar N. A New Methodology for Evaluation: The Pedagogical Rating of Online Courses. Syllabus. 2002; 15(6): 18-21.

18) Marschark M, Hauser PC. How Deaf Children Learn What Parents and Teachers Need to Know. First ed: Oxford University Press; 2011.

19) Nikolaraizi M, Vekiri I. The design of a software to enhance the reading comprehension skills of deaf students: An integration of multiple theoretical perspectives. Education and Information Technologies. 2012; 17(2): 167-85. doi: 10.1007/s10639-011-9152-1.

20) Nikolaraizi M, Vekiri I, Easterbrooks SR. Investigating deaf students' use of visual multimedia resources in reading comprehension. Am Ann Deaf. 2013; 157(5): 458-73. doi: 10.1353/aad.2013.0007. PMID: 23505841.

21) Rogers A. Learning: Can We Change the Discourse? Adults Learning. 1997; 8(5): 116-7.

22) Baskett HKM. Workplace Factors Which Enhance Self-Directed Learning. A Report of a Project on SelfDirected Learning in the Workplace. West Palm Beach Florida: Group for Interdisciplinary Research on Autonomy and Training, 1993.

23) Cahoon BB. Computer Skill Learning in the Workplace: A Comparative Case Study. University of Georgia Athens: University of Georgia; 1995.

24) Tillaart Hvd, Berg Svd, Warmerdam J. Work and Learning in Micro-enterprises in the Printing Industry. Thessaloniki: European Centre for the Development of Vocational Training, 1998.

25) Agboola IO, Lee AC. Computer and information technology access for deaf individuals in developed and developing countries. Journal of Deaf Study and Deaf Education. 2000; 5(3): 286-9. doi: 10.1093/deafed/5.3.286.

26) Liu CC, Chou CC, Liu BJ, Yang JW. Improving Mathematics Teaching and Learning Experiences for Hard of Hearing Students with Wireless Technology-Enhanced Classrooms. Am Ann Deaf. 2006; 151(3): 34555. doi: 10.1353/aad.2006.0035. PMID: 17087445.

27) Baker S. Remote Tutoring of Deaf and Hard of Hearing Students Using Video and Web based Technologies. Journal of Technology in Deaf Education. 2010; 1(1).

28) Hussein KQ, Al-Nisour A. e-Learning Modules of Tutorial Lessons for The Deaf Students: Development \& Evaluation" View Points of Experts in Consideration". International Journal of Computer Science and Network Security. 2009; 9(9): 327-37. 